\section{O Alfa e o Ômega: A vida das grandes cidades, suas fases e porque deveriam nos importar}

Daniel J. Mellado Paz

Daniel J. Mellado PAZ é Doutor em Arquitetura e Urbanismo. Professor da FA-UFBA; danielmelladopaz@hotmail.com

\begin{abstract}
Resumo
O artigo apresenta a compreensão que Jane Jacobs possui da vitalidade urbana, a partir das teorias sobre a complexidade organizada. As cidades são expressão do fenômeno universal do desenvolvimento, da ordem crescente que expulsa a entropia, onde o próprio termo vitalidade não é uma metáfora, e sim a própria raiz do fenômeno, regido por poucos e inexoráveis princípios. O Nascimento é a emergência de um novo tipo de ordem, diferente da soma das partes, com a formação de conexões cada vez mais intrincadas. Para Jacobs o Crescimento é quantitativo (a expansão) e qualitativo (a diferenciação) em um contínuo co-desenvolvimento, alimentado pelas várias formas de realimentação positiva e negativa em um universo instável, e seus efeitos ao longo do tempo. A Morte é a perda da complexidade do sistema, neste caso as cidades, e Jacobs expõe as causas e meios da incapacidade em responder às circunstâncias mutáveis, revendo o conceito de eficiência. Ela ainda tenta demonstrar as condições para sua Sobrevivência, por meio das inovações nas bifurcações, apesar dos resultados incertos e inesperados. E precisamente por essa incerteza, constitutiva da realidade, Jane Jacobs oscilará entre o desespero e a esperança.
\end{abstract}

Palavras-chave: Jane Jacobs, cidades, auto-organização.

\begin{abstract}
The paper presents the Jane Jacobs' understanding on urban vitality, derived from the theories of organized complexity. Cities are an expression of the universal phenomenon of development, the growing order that expels entropy, where the very term vitality is not a metaphor, but the very root of the phenomenon, governed by few and inexorable principles. The Birth is the emergence of a new type of order, different from the sum of the parts, with the formation of increasingly intricate connections. To Jacobs the Growth is quantitative (the expansion) and qualitative (the differentiation) in a continuous co-development, fuelled by the various forms of positive and negative feedback in an unstable universe over time. The Death is the loss of complexity in the system, in this case the cities, and Jacobs exposes the causes and ways of the incapacity to respond to changing circumstances, reviewing the concept of efficiency. She still tries to demonstrate the conditions for it Survival through innovations in the bifurcations, despite the uncertain and unexpected results. And precisely because of this uncertainty, constitutive of reality, Jane Jacobs will oscillate between despair and hope.
\end{abstract}

Keywords: Jane Jacobs, cities, self-organization.

\section{Resumen}

El artículo presenta el entendimiento de que Jane Jacobs tiene de la vitalidad urbana, a partir de las teorías de la complejidad organizada. Las ciudades son una expresión del fenómeno universal del desarrollo, del orden creciente que expulsa la entropía, en el que el propio término vitalidad no es una metáfora, pero la raíz misma del fenómeno, regido por pocos y inexorables principios. El Nacimiento es la aparición de un nuevo tipo de orden, diferente
PAZ, Daniel J. Mellado. O Alfa e o Ômega: A vida das grandes cidades, suas fases e porque deveriam nos importar. Thésis, Rio de Janeiro, v. 5 , n. 10 , p. $28-47$, dez. 2020

data de submissão: 05/06/2020 data de aceite: $27 / 10 / 2020$ 
Mesmo aquele aparentemente mais específico, sobre o separatismo de Quebec (JACOBS, 1980) está eivado dos seus conceitos sobre a cidade e seu papel econômico. É sua investigação sobre a moral (JACOBS, 1994) que mais destoa do conjunto da obra, embora se articule, em vários pontos, com sua noção de que o ser humano é uma espécie que está explorando novas possibilidades - no caso, o comércio e suas emanações éticas - justamente por ter habilidades indefinidas, em aberto. Doravante, as referências a Jane Jacobs serão em nota de rodapé, pela sua extrema recorrência no corpo do texto. E os exemplos dados serão sempre - salvo engano - extraídos de suas próprias obras.

2 Explorado com maior profundidade em dois textos, complementares (PAZ, 2011a; 2011b).

\footnotetext{
Mary Rowe se apresenta como amiga de Jane Jacobs, ao menos na última década de sua vida, e como não-acadêmica. Tinha familiaridade com os termos e princípios do pensamento dela: redes, circuitos de realimentação, auto-regulação, complexidade organizada, fractais, entre outros. Infelizmente não aprofundou mais no tema.
}

de la suma de las partes, con la formación de conexiones cada vez más complejas. Para Jacobs el Crecimiento es cuantitativo (expansión) y cualitativo (diferenciación) en un co-desarrollo continuo, impulsado por diversas formas de retroalimentación positiva y negativa en un universo inestable y sus efectos al largo del tiempo. La Muerte es la pérdida de la complejidad del sistema, en este caso las ciudades, y Jacobs expone las causas y los medios de la incapacidad para responder a las circunstancias cambiantes, replanteando el concepto de eficiencia. Ella todavía trata de mostrar las condiciones para su Supervivencia, a través de innovaciones en bifurcaciones, a pesar de los resultados inciertos e inesperados. $Y$ precisamente debido a esta incertidumbre, constitutiva de la realidad, Jane Jacobs oscilará entre la desesperación y la esperanza.

Palabras-clave: Jane Jacobs, ciudades, auto-organización.

\section{Introdução: a Cidade e sua Ordem Complexa}

J ane Jacobs (1916-2006) escreveu um tanto sobre a cidade e economia, em círculos concêntricos crescentes $^{1}$. Na área do Urbanismo, sua abordagem propunha uma impressionante inovação epistemológica que parece não teve a merecida repercussão. Talvez sequer tenha sido compreendida em toda sua abrangência, uma vez que empregava, e de maneira consciente, conceitos e termos das ciências da complexida$d e^{2}$. Para ela as cidades seriam sistemas complexos, fenômenos de complexidade organizada (WEAVER, 1958), essencialmente criativos, em todas as faces da atividade humana: cultura, economia, tecnologia.

Vale a pena dizer que Jacobs não é apenas uma arguta observadora. Não se trata da vitória do senso comum, título de uma obra de divulgação de Glenna Lang e Marjory Wunsch (2009), mas a aplicação, e costura, de conceitos e teorias que se desenvolviam em paralelo então. Mary Rowe (2014) menciona a cidade auto-organizada, e expõe o que é o cerne deste trabalho: que Jane Jacobs empregava com plena ciência conceitos oriundos dessa mudança epistemológica das ciências da complexidade. Porém não aprofunda mais além disso $^{3}$. A imagem de uma mulher observadora e com os pés no chão se estabelece, em boa medida, pelas virtudes de sua prosa, somado ao desconhecimento geral daquelas teorias, e da sua defesa desse conhecimento obtido na própria rua, do "senso comum", que gnoseologicamente é válido exatamente porque adota tais teorias. A extrema clareza de seus exemplos, e a maneira como acaba redundando, a partir da experiência das cidades americanas, em prescrições muito concretas, também acabou por escamotear a compreensão do arcabouço conceitual do seu livro mais famoso, e que se refinou nos escritos posteriores. O que the interessou de um modo geral é o enigma 
do desenvolvimento, pois "a pobreza não tem causas. Apenas a prosperidade tem causas"4 . A pobreza, como a escuridão e o frio, é ausência. Por isso o importante é entender como a presença, a prosperidade, ocorre. A pobreza fora a regra na história humana, "economias desenvolvidas tem sido exceção, e sua história (...) tem sido breve" ${ }^{\prime \prime}$. Jacobs acredita que as cidades são o resultado e o locus do desenvolvimento humano, os verdadeiros entes econômicos fundamentais, e não as nações, meras limitações de soberania. E isso "depende delas por definição porque, onde quer que vida econômica esteja se desenvolvendo, o processo em si mesmo cria cidades" ${ }^{\prime}$. O mesmo vale para os vazios da cidade, suas áreas abandonadas. Por isso que solicita que se veja a vitalidade na cidade (e das cidades no território) como lumes, fogueiras, na escuridão ${ }^{7}$. As trevas não têm forma em si mesmas, apenas são o remanescente dos lumes. A escuridão não tem substância, e nascedouro. A única positividade real é a das chamas.

O destino de todos depende em última instância das cidades: "sociedades e civilizações cujas cidades estagnam não se desenvolvem e florescem mais adiante. Elas deterioram" ${ }^{\prime 8}$. Então se pergunta por que algumas cidades crescem, enquanto outras estagnam e decaem. Toda sua obra é o intento de descobrir e revelar os princípios deste fenômeno. Até porque o colapso, a extinção, foi algo que ocorreu repetidas vezes, e paira como constante ameaça às iniciativas humanas: empresas, cidades, países, civilizações. Alternando em suas obras escritas entre a amargura pela destruição desse efervescente caldeirão, a partir das decisões tomadas pelo poder concentrado, no Estado e grandes firmas, e a esperança pelos processos de desenvolvimento e sua compreensão.

Não é ocioso insistir que a famosa vitalidade urbana deve ser compreendida no sentido literal: trata-se da própria vida em curso". Ela mesma disse: "não estou fazendo metáforas"10. Não são metáforas: são o mesmo fenômeno. Os conceitos relacionados são homólogos aos da vida biológica, e não análogos, e apresentados a seguir com os processos correspondentes e com os conceitos e exemplos expostos pela própria Jane Jacobs, porém com termos da área, nem sempre por ela empregados.

\section{Vitalidade Urbana: a neguentropia}

A cidade é entendida de maneira termodinâmica e, tal qual a vida biológica, como forma de desenvolvimento, expulsando a entropia por meio da auto-organização
4 JACOBS, 1970, p.120 - tradução nossa.

JACOBS, 1970, p.250.

6 JACOBS, 1984, p.132 - tradução nossa.

\section{JACOBS, 2003, p.419.}

8 JACOBS, 1984, p.232.

9 Não é ocioso porque a interpretação usual é a de ser uma metáfora, como na síntese da obra jacobiana feita por Gert-Jan Hospers (2006). Dirk Schuber, por exemplo, afirma claramente: "Ela frequentemente usava metáforas biológicas para explicar suas idéias" (SCHUBERT, 2014, pag. 9).

10 JACOBS, 2001, p. 24. 
1 JACOBS, 1994, p.192.

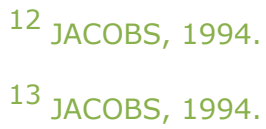

14 JACOBS, 1970.

15 JACOBS, 2001.

16 o que condiz com os suportes teóricos. A Cibernética, lastreada no conceito de feedback, pauta-se na unidade entre máquinas e tecidos vivos, e mesmo estruturas sociais (WIENER, 1980). Na Teoria do Caos, os conceitos de universalidade e bifurcações de Feigenbaum reforçam essa unidade transversal e vertical de toda a realidade (GLEICK, 1991).

17 JACOBS, 2001, p.39.

18 JACOBS, 2001, p.176.

19 JACOBS, 2001.

20 JACOBS, 2001, p.39. crescente, em um oásis neguentrópico. Todos os sistemas no planeta Terra são conduítes para a energia transiente do sol: a "vitalidade é uma manifestação da transformação de energia" ${ }^{11}$. Pelas cidades, como nos ecossistemas, circulam recursos, a matéria-prima e a produção humana, e não no sentido usual do capital. Como um ecossistema, o fundamental não é reter a energia, e sim fazê-la passar pelo maior número possível de caminhos, alimentando o sistema e realizando mais trabalhos.

A luz do Sol, uma vez captada no conduto, é não apenas transformada mas retransformada, combinada e recombinada, processada e reprocessada, à medida que a energia-matéria vai passando de organismo para organismo. (JACOBS, 2001, p. 58).

Um corolário importante é que nem sempre o universo se apresenta como um jogo de soma zero, com um mesmo quantum de energia, recursos, dinheiro, que precisa ser deslocado para lá e para cá. O fenômeno da auto-organização, da vitalidade, "cria" e aumenta este quantum. O comércio seria assim" ${ }^{12}$, como os necessários ajustes para tecnologias limpas ${ }^{13}$, ou a renda dos lugares - referindo-se à crença de que o excesso de gente causaria a pobreza, o que seria falso, visto a ineficácia de despovoar uma área para aumentar a renda individual ${ }^{14}$. Contra a concepção da lei dos rendimentos decrescentes no uso dos recursos, uma lei de rendimentos crescentes, a partir do trabaIho humano ${ }^{15}$.

As leis do universo seriam válidas em todas as suas escalas $^{16}$. O desenvolvimento econômico "utiliza os mesmos princípios universais utilizados pelo resto da natureza"17. Quando negligenciados, simplesmente não ocorre o desenvolvimento. Era "estúpido tentar contornar processos universais"18. Não compreendê- Ios leva fatidicamente em adotar medidas que sustarão o desenvolvimento, levando à entropia. Ao contrário, todo desenvolvimento humano teria se ajustado a tais princípios, ainda que de maneira intuitiva, por tentativa e erro: o idioma ${ }^{19}$, as ferramentas humanas, a economia, a cidade. O desenvolvimento das criações humanas "é uma versão do desenvolvimento natural"20, visto que

a vida econômica é regulada por processos e princípios que não inventamos e não podemos ignorar, gostemos ou não disso, e que, quanto mais aprendermos e respeitarmos esses processos, melhor irá nossa economia. (JACOBS, 2001, p.18).

São quatro princípios, porque "a natureza é pródiga com detalhes, mas parcimoniosa com princípios"21: a 
diferenciação emergindo de generalidades, o co-desenvolvimento, a expansão pelo uso múltiplo e diverso de insumos e a auto-manutenção pelo auto-reabastecimento.

\section{Nascimento: ativação e emergência}

O nascimento se dá com a emergência de um novo tipo de ordem, com sua ativação. As grandes cidades, por exemplo, não são espécies do mesmo gênero que as pequenas cidades.

Quando se ultrapassa a densidade habitacional de um semi-subúrbio ou uma localidade de subúrbio é engolida, passa a existir de repente um tipo totalmente diverso de núcleo urbano (...) até o ponto em que uma vida urbana autêntica começa a surgir e suas forças construtivas passem a atuar. (JACOBS, 2003, p.232).

Após certo tamanho, modificam-se: as modalidades de associação, agora amparada na rede informal; a privacidade, com a aparição do estranho e o controle do comportamento a partir dos visitantes desconhecidos. Também entre o parque de bairro e o urbano, as paradas de trem e a linha férrea, a mudança de escala tem implicações sérias. As condições da ativação, em que a cidade começa a ganhar complexidade como o momento em que o subúrbio se torna um distrito pujante, são preocupação central em Jacobs.

$\mathrm{Na}$ complexidade organizada os elementos interagem para além das meras perturbações locais, assumindo papéis diferentes entre si e criando conexões, com circulação de informação, ganhando organização em um sentido bottom-up ${ }^{22}$. O todo se torna diferente da soma das partes, com propriedades que emergem, irredutíveis aos seus componentes, e mesmo imprevisíveis no comportamento, apresentando aprendizado e adaptação. Tais conexões criam uma estrutura interna funcional que se distribui de maneira escalar. No caso da cidade, seriam a vizinhança, o distrito e a cidade mesma. Não admite a nação como unidade funcional, econômica.

Cidades são as unidades econômicas específicas que podem substituir exportações por sua própria produção, e as unidades específicas que produzem levas de novos tipos de exportações. É inútil supor que as coleções estatísticas indiferenciadas e amorfas das economias nacionais perfazem estas funções, porque não o fazem. (JACOBS, 1984, p.162).

A tessitura geral da vida urbana forma-se a partir de ações individuais que reforçam as dos demais por meio de efeitos laterais ao propósito original, nem
2 Steven Johnson (2003) faz ênfase nesse processo e reconhece em Jacobs a sua inovação em pensar de tal maneira a cidade. 
23 JACOBS, 2003. Tal processo depende, porém, de configurações físicas, mote de sua primeira obra: ruas constantes, trama contínua, calçadas generosas e olhos voltados para a rua, variedade de pontos de encontro. Com tais elementos, a trama se estabelece, organizando o sistema.

24 JACOBS, 2003, p.131.

25 JACOBS, 2003, p.168.

26 JACOBS, 2004.

27 JACOBS, 2003, p.147

28 JACOBS, 2003, p.61.

29 JACOBS, 2003, p.146. sempre conscientes, ainda assim indispensáveis para constituir a ordem complexa ${ }^{23}$. A exemplo das "redes de vigilância pública" ${ }^{24}$ que cumprem o papel de segurança, contato e integração infantil à cidade. Ou como ocorre entre moradores e trabalhadores, pois "os empreendimentos que somos capazes de manter atraem, para as calçadas, à noite, muito mais moradores do que se o lugar fosse morto"25.

A soma desses contatos públicos casuais no âmbito local (...) resulta na compreensão da identidade pública das pessoas, uma rede de respeito e confiança mútuos e um apoio eventual na dificuldade pessoal ou da vizinhança. (JACOBS, 2003, p.60).

Não é meta do transeunte propiciar segurança, nem dos moradores à rua vigiar a vizinhança, ou dos estabelecimentos comerciais serem locais de encontro, ou do entorno animado sustentar os parques públicos: são apenas o efeito lateral de sua existência. Como é o papel informal, e muitas vezes intangível, que a rede de conhecidos desempenha nas famílias e na formação de crianças $^{26}$, das pequenas comunidades do interior às cidades.

Mesmo uma sociedade pobre pode prover redundância de mentores e exemplos, porquê pessoas em suas comunidades preenchem estes papéis enquanto se realizam levando suas vidas por outros meios (...) visíveis em uma comunidade, mas invisíveis aos jovens quando a comunidade se torna invisível. (JACOBS, 2004, p.158 - tradução nossa).

Além dessa trama acidental, há nexos humanos mais consistentes, verticais e horizontais. Podem ser poucos para constituir o "o distrito como uma Entidade real. Bastam cerca de cem pessoas numa população mil vezes maior" 27 . As associações humanas mais distantes ou específicas dependerão do excesso de contatos humanos, dessa "vida pública informal subjacente, interpondo-se entre elas e a privacidade da população urbana"28. Aquela rede de vigilância pública é o pano de fundo para conexões mais intensas do que chama figuras públicas, das quais dependem as lideranças formais, na escala da vizinhança. Na escala dos distritos existem "pessoas, geralmente líderes, que ampliam sua vida pública local para além da vizinhança e de organizações ou instituições específicas" ${ }^{29}$.

A ordem complexa emergirá de ações locais, realizadas a partir de informações que são manifestações locais do todo. Prescinde-se de uma compreensão global. Basta atenção aos indicadores.

Qualquer cidadão, repito, pode ter consciência dos indícios irregulares - ou consciência de sua ausência. 
Os habitantes das cidades, na verdade, geralmente são ótimos especialistas informais exatamente nesse assunto. (JACOBS, 2003, p.493).

Como a solicitude das crianças, a panfletagem, o número de bancos e companhias de seguro, a iluminação pública, aponta a integração infantil à vida urbana, a diversidade do parque de bairro, a perda de diversidade de uma região ou lugares desertos, respectivamente. São os sinais interpretados por todos e cada um, e por Jacobs em sua investigação. A expressão da ordem complexa ao nível da rua, de modo que possa ser empiricamente observada por qualquer um, é parte do fenômeno e a condição epistemológica de seu trabalho. Por isso que pessoas comuns são capazes de perceber quando um distrito é próspero ou decadente com mais agudeza que os planejadores; há casos em que "os indícios visíveis do processo de degradação são quase tão gráficos como um diagrama"30. O sistema é complexo, mas comunica sua situação em todos níveis por meio de sinais relativamente simples, de apreensão fácil. O "senso comum", que tanto aplicam a Jacobs positiva ou negativamente, é processo de conhecimento válido e, mais importante, é a base da tomada de decisões dos agentes humanos mais simples, mais elementares. Aqui os sinais devem ser entendidos exatamente como tais: são fluxos de informação. E se corrompidos terão efeitos devastadores.

\section{Crescimento: diferenciação e expansão}

As cidades crescem em dois sentidos distintos. Sua melhoria qualitativa, sua complexificação, será o desenvolvimento. Seu aumento quantitativo, uma expansão. Um ecossistema em desenvolvimento aumenta a biodiversidade; em expansão, a biomassa. A expansão de um rio seria o aumento do volume de água; o desenvolvimento, a formação de um delta ${ }^{31}$. A expansão de um ente ocorre pela eficiência em capturar a energia transiente. O importante, no entanto, será o desenvolvimento, "processo aberto que cria complexidade e diversidade, porque múltiplas generalidades são fontes de múltiplas diversificações"32.

A complexidade se incrementa pela diferenciação, como na morfogênese das células humanas ${ }^{33}$, processo que vale do sistema solar até o labor humano. As primeiras ferramentas foram generalidades (ossos, pedras, galhos) que, em graus sucessivos de especialização, ganharam a forma de martelos, lanças, foices. O mesmo com as formas de atividade produtiva, que "multiplicam-se em mais divisões de trabalho
30 JACOBS, 2003, p.288.

31 Metáfora do biólogo C.H. Waddintgon para descrever a paisagem epigenética (ELLERMAN, 2004).

32 JACOBS, 2001, p.24.

JACOBS, 2001. O trabalho pioneiro nesse aspect foi o de Alan Turing, The Chemical Basis of Morphogenesis (Philosophical Transactions of the Royal Society of London. Series B, Biological Sciences, Vol. 237, No. 641. aug. 1952), onde matematicamente demonstrava o desenvolvimento de um embrião (no sentido de Jacobs) por meio da diferenciação crescente. Este foi um dos textos inaugurais dos estudos da complexidade auto-organizada. 
34 JACOBS, 1970, p.58 - tradução nossa.

35 JACOBS, 1970, p.55 - tradução nossa.

36 JACOBS, 1970; 1984

37 JACOBS, 1970.

38 JACOBS, 1980, p.68 - tradução nossa.

39 JACOBS 1984; 1994.

40 JACOBS, 2003, p.161.

41 JACOBS, 2003, p.314. por meio da adição de atividades que produzem novas somas de trabalho para ser dividido" ${ }^{\prime 34}$. Diferenciação incremental, na maioria dos casos, onde uma nova atividade "é adicionada diretamente a apenas um fragmento do trabalho anterior" 35 , a uma de suas etapas; que passará por nova divisão do trabalho, que terá uma etapa sua mesclada com outras, e assim por diante. Como a invenção do sutiã por Mrs. Rosenthal derivada da confecção de vestidos, ou a produção de adesivos pela $3 \mathrm{M}$, que originalmente produziam areias abrasivas para metalurgia ${ }^{36}$. A divisão do trabalho de Adam Smith é apenas um take de um processo de divisão, secessão e diversificação da atividade. O clássico exemplo da produção de alfinetes fora uma especialização dos manufaturados de arame ${ }^{37}$.

A diferenciação é, ao cabo, a inovação. Em um momento, Jacobs (1980) comparará a divisão das atividades à bipartição das amebas. Ao falar de que as novas partes não são idênticas às anteriores, emprega o termo mutação. Trata-se de um outro nome para esse processo incremental, pois "mutantes são a mais importante forma de divisão na vida econômica"38. Outro conceito que emprega é o de epifenômeno cooptado, de Stephen Jay Gould, que descreve a transformação dos órgãos de uma função a outra nos organismos vivos. Jacobs o aplica culturalmente, a exemplo do rádio, cooptado para o entretenimento, criado para mensagens emergenciais ${ }^{39}$. Por isso, a vitalidade econômica é um indício da mesma pujança, da complexidade crescente, que será a vitalidade cultural.

As mesmas condições físicas e econômicas que geram um comércio diversificado estão intimamente relacionadas à criação, ou à presença, de outros tipos de variedade urbana. (JACOBS, 2003, p.162).

Essa diversidade na cidade é a de atividades comerciais e culturais, de criações técnicas e artísticas, de tipos edilícios e mesmo de seres humanos. A variedade de seres humanos, pessoas com "os mais diferentes gostos, habilidades, necessidades, carências e obsessões" ${ }^{\prime \prime 0}$. A complexificação do ambiente inclui a diversificação "progressiva da própria população. (...) As qualificações, os interesses, as atividades e as relações distintas fora do bairro variam e se diferenciam com o passar do tempo"41. A diversidade é resultado e causa do processo de organização crescente. De entrada, facilita a expansão do sistema.

Quanto mais diferenciados forem os meios que um sistema possui para recapturar e transferir energia, antes que seja descarregada do sistema, maiores são os efeitos cumulativos da energia que ele recebe. (JACOBS, 2001, p.59). 
Estabelece ainda relações intrincadas dos seres entre si, com o seu entorno, que é igualmente parte do fenômeno, na medida em que todos vão se transformando. Um habitat natural, por exemplo, é "uma rede intrincada, complicada de interdependências" ${ }^{42}$.

Desenvolvimento depende de co-desenvolvimento. Quero dizer que não adianta pensar o desenvolvimento "linearmente", ou mesmo como um conjunto de linhas abertas. Ele opera como uma rede de co-desenvolvimentos interdependentes. Sem essa rede não há desenvolvimento. (JACOBS, 2001, p.26).

Nas cidades existe co-desenvolvimento em todas as esferas: dentro do mecanismo da aparição de novas atividades, a variedade de bens e serviços do entorno permite com mais facilidade a montagem de novas cadeias de trabalho, e o consumo dos novos bens produzidos, às vezes por outros produtores, para confeccionar seus próprios bens.

As cidades ainda irradiam desenvolvimento. As cidades seriam o motor da civilização, estruturando a zona rural desde a pré-história ${ }^{43}$. $O$ processo de subsumir o campo à cidade é um dos três sinais de economias em expansão e desenvolvimento ${ }^{44}$. Dentre as maneiras pelas quais as cidades se expandiriam, são modalidades que reorganizam a zona rural: o aumento repentino do mercado consumidor urbano para os produtos rurais, o transplante de atividades da cidade para o campo e as aplicações de inovações que multiplicam as mercadorias produzidas e expandem o seu volume $^{45}$. Por ação das cidades, come-se não apenas mais, como melhor, como no Japão do pós-guerra ${ }^{46}$. Toronto seria um exemplo da colonização do entorno rural por empreendimentos surgidos na cidade, e Montreal, da capitalização do seu próprio entorno por consumo e investimentos ${ }^{47}$. Invenções como o sistema de três campos do séc. XII, a revolução agrícola do séc. XVIII, a segadora de Cyrus McCormick, os grãos híbridos atuais, foram todas gestadas em cidade. Benfeitorias exportadas à zona rural, como a eletricidade, também. Não era coincidência a agricultura ser mais produtiva nos países mais urbanizados, nem a fome da Irlanda relacionar-se à carência das benfeitorias espraiadas das cidades. Igualmente, ao substituir importações por inovações técnicas, as cidades tornam obsoleta a produção do entorno e áreas distantes: como a produção artificial do gelo, o couro artificial, a borracha sintética, as roupas sem algodão ${ }^{48}$.

Assim, é a pulsão das cidades que comanda o tipo de atividade rural. Sua "habilidade de modelar e remo-
42 JACOBS, 2001, p.29.

43 JACOBS, 1970.

44 JACOBS, 1984.

45 JACOBS, 1984

46 JACOBS, 1970.

47 JACOBS, 1980; 1984.

48 JACOBS, 1970 
49 JACOBS, 2004, p.32 - tradução nossa.

50 JACOBS, 2001, p.113.

51 JACOBS, 2003, p.159.

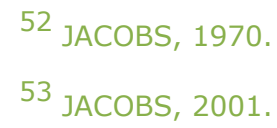

O termo - import-replacing tem um sentido particular na teoria econômica de Jane Jacobs, que não cabe aqui expor. E não aquele que o termo substituição de importações tem usualmente.

55 JACOBS, 2003.

56 JACOBS, 2004.

57 JACOBS, 2001. delar as economias de outros assentamentos"49 inclui mesmo aquelas geograficamente distantes.

As realimentações (feedback) são parte da estrutura dos fenômenos complexos, da cidade, e da auto-organização em geral, que "pode ser transmitida por diversos meios - monetário, demográfico, mecânico, químico, elétrico, o que for ${ }^{\prime \prime 50}$ e é

\begin{abstract}
essencial aos sistemas dinâmicos, conspicuamente incluindo sistemas ecológicos e bioquímicos e desenvolvimento neurológico infantil; realimentação é tão essencial nestes sistemas que se eles param ou falham, o sistema por inteiro morre ou, dito de outra maneira, falha. (JACOBS, 2004, p.69 - tradução nossa).
\end{abstract}

Na sua primeira obra sobre a cidade, Jacobs menciona apenas as realimentações positivas. Círculos virtuosos, como o das pessoas às ruas, pois "a presença as pessoas atrai outras pessoas", a recuperação dos cortiços, a pluralidade comercial de uma cidade e, de um modo geral, da diversidade, porque a "própria diversidade urbana permite e estimula mais diversidade"51. Em outro momento, ao tratar de economia urbana, fala de sistemas recíprocos, ciclos de realimentação positiva como a musculatura que opera os pulmões que por sua vez a sustentam ${ }^{52}$, e de mecanismos de auto-abastecimento ${ }^{53}$. A cidade, em si, é uma expressão do fenômeno.

Qualquer assentamento que se torna bom em substituir importações torna-se uma cidade. (...) Na vida real, onde quer que substituição de importações ocorre significantemente, se dá em episódios explosivos porque trabalha como uma reação em cadeia. (JACOBS, 1984 , p.41 - tradução nossa) $)^{54}$.

Porém a deterioração da complexidade é, também, um processo de realimentação, círculos viciosos, como o ciclo da insegurança nas ruas, os parques vazios, os especuladores e a remoção de cortiços, os cortiços e os projetos de reforma urbana, a proliferação dos automóveis na cidade ${ }^{55}$. $E$, em um grau maior, nacional, a relação entre o déficit habitacional, desmantelamento de comunidades e dependência excessiva dos automóveis ${ }^{56}$. Jacobs acredita que os ciclos econômicos de realimentação positiva daninhos são em geral subsidiados, como a falência dos bancos pesqueiros de Grand Banks por superexploração ${ }^{57}$. Apesar de breves, tais processos podem ser portentosos, e concluem com o colapso.

Em obras posteriores incluiu a realimentação negativa. A realimentação positiva tende a intensificar a instabilidade, corrigida pela realimentação negativa, 
"sistemas instáveis requerem correções contínuas e ajustes, de outra maneira em pouco tempo sucumbirão por suas próprias instabilidades" ${ }^{\prime 58}$. Enumera como exemplos o termostato e, no plano sociológico, a queda do valor do papel-moeda como resposta à sua impressão, a saída de empreendimentos urbanos devido ao apinhamento e concorrência crescente pelo espaço ${ }^{59}$. Em mais de uma ocasião cita e adota como exemplo a "mão invisível" descrita por Adam Smith ${ }^{60}$. Porque, em verdade, adota a concepção de Ludwig von Mises, aprimorada nesse aspecto por Friedrich von Hayek, de que o preço é um sinal local de um arranjo global (o custo de cada produto), correndo em sentido inverso ao do fluxo de produtos, símbolo do crédito que alguém que produz algo adquire perante os demais, feedback negativo para "a auto-regulamentação econômica" 61 . Assim, permite o rearranjo eficiente das forças produtivas; preços altos estimulam produtos novos, mais baratos, como os tipos móveis em relação aos livros manuais, ou o revestimento de madeira dos cabos dos talheres no lugar da prata62. Quando corrompido - por subsídios, impostos, bolhas especulativas $^{63}$ - desregula-se o sistema. Em obra específica, acredita que políticas nacionais, na medida em que a maioria das nações não coincidem com as cidades como unidades econômicas, igualmente falseiam os dados ${ }^{64}$.

Mas o desafio é o da própria sobrevivência em um universo instável. A estabilidade dos sistemas - "sistemas vivos, ecossistemas, organismos, células que compõem organismos, microrganismos", como "muitos sistemas inanimados: os rios, a atmosfera, a crosta terrestre. Coletividades humanas, empresas, economias, nações, governos, civilizações" ${ }^{\prime 65}$ - implica no risco da instabilidade.

Nenhum sistema dinamicamente estável vive para sempre (...). Mas o milagre é que esses sistemas vulneráveis resistem, se sucedem e florescem cada um a seu tempo, sob o Sol. Sistemas dinâmicos têm recursos e métodos para evitar colapsos. (JACOBS, 2001, p.103).

Seriam quatro os meios para manter a estabilidade: os ciclos de realimentação positiva e os controles de realimentação negativa, além das bifurcações e adaptações de emergência.

O processo de diversificação ao longo do tempo inevitavelmente conduz a uma variedade de elementos. $\mathrm{Na}$ cidade essa diversidade (econômica, edilícia, humana) é o que lhe permite singrar os mares futuros. A história do sistema está cristalizada na própria estrutura,
58 JACOBS, 1984, p.158 - tradução nossa. Não é uma invenção de Jane Jacobs. Norbert Wiener, o pai da Cibernética, cedo descobriu que a realimentação negativa é o princípio da homeostase (WIENER, 1970; 1980). Wiener, cujas descobertas são mencionadas rapidamente nas obras iniciais de Jacobs, depois ganha pleno reconhecimento (JACOBS, 2001).

\section{JACOBS, 1984. \\ 60 JACOBS, 2001.}

61 JACOBS, 2001, p.19.

62 JACOBS, 2001.

63 JACOBS, 2001.

64 JACOBS, 1984. A exceção será aqueles países que são, na prática, cidades-estado (Singapura, Hong Kong, Holanda) ou de porte similar (Taiwan).

65 JACOBS, 2001, p.103. 
66 A memória humana, neurológica, em si mesma é estrutura. Portanto, tampouco é uma analogia.

67 JACOBS, 2003, p.60.

68 JACOBS, 2003, p.348.

69 JACOBS, 2003, p.149.

70 JACOBS, 2003.

71 JACOBS, 2003, p.220.

72 JACOBS, 2003, p.308. JACOBS, 2003. nas suas conexões e entidades. Sua forma em cada instante é resultado de todas as etapas pregressas, de maneira singular e irreversível. De certa maneira seria como ter uma memória66. Ilya Prigogine (2002) observa que o homem neolítico é, individualmente, tão inteligente quanto o contemporâneo; o que é radicalmente diferente são as relações entre os homens e seu passivo, intelectual e material. Está na estrutura, formada com o passar dos milênios. A confiança, por exemplo, que ocorre na rua e na vizinhança, "forma-se com o tempo a partir de inúmeros pequenos contatos públicos nas calçadas ${ }^{\prime 67}$. Os empreendimentos pessoais, os negócios de bairro, são concretizações das pessoas e suas famílias, "todo o seu passado transformado em esperança de futuro"68, daí a crítica às desapropriações. O mesmo vale para os relacionamentos humanos em geral, insubstituíveis, e alerta que, quando desfeitos, "destrói-se sua condição de seres sociais verdadeiros - às vezes por pouco tempo, às vezes para sempre" ${ }^{\prime \prime 9}$. O poder político dos distritos também vem com o tempo ${ }^{70}$. Os próprios edifícios da cidade provêm das sedimentações históricas e aí radica seu valor. Pois, com custo amortizado pelo passar dos anos, os prédios mais antigos permitem empreendimentos de menor retorno e moradores com menor renda, e com isso sua maior variedade na cidade ${ }^{71}$.

O problema se instala quando o tempo é zerado por alguma forma de tabula rasa, destruindo a complexidade daquele sistema adquirida no correr dos anos. Remover pessoas constantemente de um lugar é uma forma dessa terraplenagem, pois, como a flutuação populacional dos cortiços, "deixam a comunidade num estágio embrionário eterno, ou num retorno eterno a uma infância desassistida"72. Outra, evidente e mote de sua ação política, era a destruição massiva de áreas da cidade e construções ex nihilo de grandes glebas de uma só vez.

\section{Morte: a entropia}

Mas há a entropia. A morte física dos seres vivos é um fenômeno desse tipo. Ocorre quando o sistema cessa de adquirir complexidade e, diante de novas circunstâncias, não se adapta, perde organização, até desfazer-se.

Todos os sistemas dinâmicos correm o risco de sucumbir à instabilidade, e é por isso que precisam de constante autocorreção. Se e quando um sistema dinâmico perde definitivamente a estabilidade, ele ou cai na inércia ou se desintegra. (JACOBS, 2001, p.103). 
A exemplo da definição de um bairro mal-sucedido para Jacobs: "é aquele que se encontra sobrecarregado de deficiências e problemas e cada vez mais inerte diante deles"73. Ao cabo, manter-se no mesmo lugar não é uma possibilidade. Não há estabilidade, a longo prazo, no universo. Não há um status quo ao qual se manter. Sequer cabe simplesmente estocar coisas como a riqueza, a cultura ou a informação, até porque não são "coisas", e sim processos. Seguir adiante é a única solução. Por exemplo, se uma cidade não realizar o que preconiza "sua economia não apenas pára de crescer; ela definha e cresce cada vez menos" ${ }^{\prime 74}$.

Uma técnica qualquer não pode ser preservada em si mesma, por exemplo; pode apenas ser assimilada a outro fim. Jacobs dizia haver hoje mais barcos à vela que antes do vapor, embora dedicados exclusivamente ao lazer; mais pessoas que sabem pôr ferraduras em cavalos que antes, embora veterinários e especialistas em animais, e não mais ferreiros; que o quimono ganhara sobrevida como roupa formal de alta moda, com zíper e novos materiais; que o chip de computador estava empregado uma técnica de joalheria quatrocentista ${ }^{75}$. Como o desenvolvimento não é um jogo de soma zero, as inovações sequer implicam na substituição das invenções anteriores por si só, elas não preenchem "um volume equivalente ao das coisas antigas que a geraram (...) nem na vida econômica nem no resto da natureza"76. O contrário é sua perda, a atrofia do conhecimento em uma dada cultura. A regra seria "use-a ou perca-a", e a história daria exemplos de retrocessos tecnológicos consideráveis; cita o papiro egípcio, os tasmanianos, pequenas cidades norte-americanas ${ }^{77}$, e mesmo civilizações como a Mesopotâmia e a China ${ }^{78}$. As técnicas se extinguem pela estagnação econômica, pela falta de dinamismo em uma sociedade ${ }^{79}$.

O que ocorre com o ente que se desagrega? O que ocorre com todos os seres vivos: são reabsorvidos por outros seres. Como na massa falida das empresas. E assim, "talvez alguma coisa dinamicamente estável o engolfe ou alguma coisa nova se organize a partir de seus fragmentos" ${ }^{\prime 80}$.

Nem sempre a diminuição das coisas - nações, sistemas, empresas, seres vivos - é uma etapa do declínio e colapso, como também parte do processo de multiplicação, um sinal de vigor, como a cissiparidade das amebas. Seria o caso tanto da separação da Noruega da Suécia, como da divisão da Standard Oil e do processo de formação de cadeias de restaurantes ${ }^{81}$.
73 JACOBS, 2003, p.123.

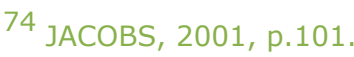

75 JACOBS, 1970; 2001.

76 JACOBS, 2001, p.54.

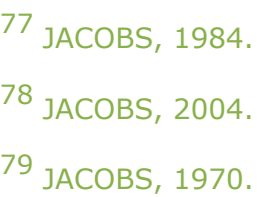

80 JACOBS, 2001, p.103.

81 JACOBS, 1980. 
82 JACOBS, 2003.

83 JACOBS, 1970.

84 JACOBS, 2001.

85 JACOBS, 1970.

86 JACOBS, 1970; 2004.

87 JACOBS, 1984.

88 JACOBS, 1980.
De toda sorte, a morte termodinâmica é a perda da complexidade do sistema. Ou, ao revés, a perda de complexidade significa a própria morte. A especialização funcional, nos sistemas humanos - empresas, áreas urbanas, cidades, países - é o sinal, a causa e o próprio declínio. Como explícito desde seu primeiro livro ${ }^{82}$, é usual que a entropia seja uma decisão consciente, embora desastrosa. Para ela, as grandes empresas não seriam um sinal de uma economia próspera. Se a inovação vem da pluralidade de empreendimentos humanos, o processo de concentração das mesmas em grandes organizações, resultado da criatividade econômica passada, só pode levar à estagnação ${ }^{83}$. O mesmo vale para monopólios, de todos os tipos, já que não há monopólios na natureza. Eles, como os de companhia de eletricidade, telefônica e dos correios ${ }^{84}$, abortam a possibilidade de inovações. Análogas são as grandes áreas de monocultura agrícola, cujo caso mais dramático talvez tenha sido a catástrofe ecológica do Usbequistão com o dessecamento do Mar de Aral. Análoga ainda é a renovação urbana de East Harlem ou do Morningside Heights, que resultou na deterioração econômica da área. $\mathrm{E}$, de um modo geral, a concepção urbana de que cada área precisa ter uma função específica, sem mesclas e sobreposição ${ }^{85}$. Ainda mais se a especialização é de cidades, ttanto para a moderna Detroit, como para a paleotécnica Manchester, a medieval Dinant e a ancestral Mohenjo-Daro ${ }^{86}$, sempre prenúncio e causa de sua decadência. Limitação similar teriam as Ilhas Canárias com o açúcar, Sardenha com o queijo e Zâmbia com o cobre ${ }^{87}$. O Uruguay teria uma economia de Terceiro Mundo, mesmo quando próspero, por sua especialização e limitação econômica. O Canadá seria um país com províncias inteiramente montadas sob um raciocínio "colonial", ancorado na exportação de matérias-primas e com cidades mono-funcionais, centros de serviço, que findo o boom econômico, decaem. Situação reforçada por mecanismos legais e financeiros orientados para isso, com grandes montantes para grandes empreendimentos ${ }^{88}$.

Aqui um parêntese importante. Repetidas vezes ela defende que uma concepção equivocada, pseudocientífica, do Urbanismo e da Economia, leva a tais medidas. No entanto assume que a própria vitalidade pode conduzir, a partir do êxito econômico, à sua própria extinção, com o aumento do interesse pela área e, portanto, do custo do solo, elitizando seus moradores e afunilando os empreendimentos para aqueles mais rentáveis, como ocorrera com a especialização da Rua Oito em restaurantes, da Rua Três com casas noturnas, e do centro de Manhattan com edifícios de 
escritórios e sedes de bancos (cuja presença assinala indefectivelmente o processo). Seriam falhas na realimentação, como ocorrem com algumas células ${ }^{89}$. São igualmente limites a servidão, as castas, a escravidão e o machismo ${ }^{90}$. Tanto na escala urbana, quanto no das civilizações: teria sido uma das conseqüências, e a seguir um reforço no círculo vicioso, da decadência da Mesopotâmia muçulmana ${ }^{91}$. Limitando a diversidade dos seres humanos, vedam possibilidades criativas. Migrando de tais lugares, fecundam aqueles que os recebem.

Outro problema está com as adaptações de emergência, medidas tomadas em tempos de crise que, mantidas para além das circunstâncias que as requisitaram, podem sacrificar a complexidade do sistema e iniciar uma escalada de deterioração. Por exemplo, Jacobs acredita que o círculo vicioso que desfaz as comunidades norte-americanas surgiu das adaptações de emergência da Grande Depressão ${ }^{92}$. A certas medidas Jacobs chama de operações de declínio, tentativas governamentais de sustar a decadência: prolongada produção militar, prolongados subsídios para regiões pobres e promoção de comércio entre economias avançadas e atrasadas ${ }^{93}$. Como se baseiam em premissas falsas, igualmente agravam a situação.

O problema residirá no conceito de eficiência. Que, para Jane Jacobs, se ancora na própria sobrevivência.

\section{Sobrevivência: bifurcações e inovações}

O conceito usual de eficiência relaciona-se com a performance em cumprir uma função específica, firmando-se nos Estados Unidos especialmente sob a forma da economia de escala.

Os heróis populares da eficiência de escala - Eli Whitney, Henry Ford, e legiões de experts em suas fileiras - muito tempo atrás convenceram políticos e populações norte-americanos que as economias de escala foram responsáveis pelos altos padrões de vida da América, o que é em parte verdade. (JACOBS, 2004, p.157 - tradução nossa).

Essa concepção é antitética ao emaranhado ambíguo, efervescente e em aberto dos sistemas complexos. Nele a mescla e ambivalência, sem respostas unívocas e funções estáveis, são essenciais. Não se pode perguntar, por exemplo, para quê serve uma economia ${ }^{94}$, como seria descabida a mesma pergunta para a natureza, pois "a vida econômica permite desenvolver culturas e uma infinidade de aspirações, e essa (...) é

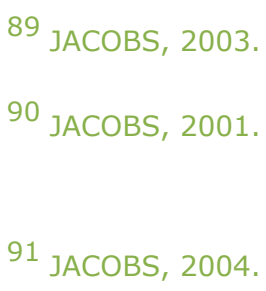

92 JACOBS, 2004. 93 JACOBS, 1984. 
95 JACOBS, 2001, p.177.

96 JACOBS, 1970 .

97 JACOBS, 2001, p.98.

98 JACOBS, 2001. Inspirado em um conceito da Teoria do Caos, as bifurcações de Feigenbaum.

Alinha-se, por exemplo, nas teorias paleontológicas, com a do equilíbrio pontuado, de Stephen Jay Gould, que Jacobs menciona algumas vezes, de que a evolução não se deu de maneira contínua.

100 ACOBS, 2001. Inspirado em artigo de John Horgan, From Complexity to Perplexity, publicado na Scientific American, de junho de 1995

101 JACOBS, 2001, p.104. a sua mais significativa função"95. Por isso uma cidade não pode ser eficiente e simultaneamente produzir atividades. É mais barato projetar e construir grandes empreendimentos de moradia, que carecem de vitalidade urbana. É mais conveniente o empréstimo de grandes montantes de capital a poucas empresas, porém menos efetivo. O treinamento de uma pessoa para um trabalho apenas é o que custa menos, porém é o mais limitante ${ }^{96}$.

A diversidade nos sistemas complexos confere-lhes resiliência para as turbulências; nos ecossistemas "os protege da devastação total por doenças ou por alterações climáticas que destroem monoculturas" ${ }^{\prime \prime 7}$. Mas também são o manancial para as novidades que permitirão o sistema saltar para um novo estado.

De fato, o trabalho de desenvolvimento é inerentemente tão incerto que pela lei dos grandes números [de Jakob Bernoulli], as chances de sucesso aumentam enormemente se houver maior número de tentativas. (JACOBS, 1970, p.90 - tradução nossa).

São as bifurcações ${ }^{98}$, situações em que os sistemas se defrontam com o colapso ou estados ainda mais complexos, seguida de novas bifurcações, interpretando o ruído exterior como insumo para um caminho novo ${ }^{99}$.

Não é acidental, mas estrutural à vida, e também às cidades, esse fio da navalha, andar "no limiar do caos $^{\prime 100}$, entre a estabilidade extrema dos cristais, ou da Cidade-Jardim de moldes corbusianos, e o caos absoluto dos fluidos em turbulência, ou das contínuas renovações dos cortiços. Deterioração e desenvolvimento, entropia e neguentropia, se apresentam como caminhos em cada bifurcação. Pois "quando a instabilidade de um sistema - seja ela de qualquer natureza - se torna tão séria que não é mais possível continuar operando como antes, ele deve fazer uma mudança radical" ${ }^{101}$. Mas pode seguir-se o fiasco, isto é, o processo entrópico:

Perdedores são confrontados com abalos tão radicais em circunstâncias tais que suas instituições não conseguem adaptar-se adequadamente, tornam-se irrelevantes, e colapsam. (JACOBS, 2004, p.20).

A definição se enquadra no caso dos bairros mal-sucedidos, porém vale o raciocínio para unidades menores, como empresas. As bifurcações urbanas bem-sucedidas levam à sua mudança de feição. Quem poderia hoje dizer que Londres iniciou sua longa vida exportando peixes? Assim como Paris, vinho; Veneza, sal; Roma, gado e Copenhague, arenque. Detroit passou de exportar farinha, para barcos e cargueiros a vapor, 
depois cobres e manufaturados, e por fim automóveis. $E$ aqui estará a diferença entre a vida e a morte. As más adaptações no mundo natural significam extinção, e "correções benévolas da deterioração não são garantidas" 102 .

Algumas pessoas pensam de modo otimista que se as coisas se tornarem ruins o suficiente, melhorarão por causa da reação de pêndulos benévolos. Quando uma cultura está funcionando bem, o balanço de pêndulos benévolos - a realimentação efetiva - ocorre. Estabilização corretiva é um dos grandes serviços da democracia, com sua realimentação aos governantes de protestos ao voto público. Estabilização é também um dos grandes serviços de algumas inovações comerciais que, junto com os mercados, afastam a produção e o consumo daqueles recursos afligidos pelos altos custos dos retornos minguantes, e os substituem por aqueles de outros locais. (JACOBS, 2004, p.21 - tradução nossa).

Se em seu primeiro livro estava preocupada com a destruição das grandes cidades norte-americanas por conta de concepções urbanas equivocadas ${ }^{103}$, no último, acreditava que EUA e Canadá estão passando por um processo de dissolução. Como tudo estaria entrelaçado, a falha em aspectos cruciais levaria um desmoronamento gradual, em realimentação positiva da degradação.

O caminho do futuro é imprevisível. Terá de ser prospectado, encontrado por tentativa e erro. Porque "ninguém pode prever os meios adequados - sem falar no 'melhor' meio - de fazer coisas conhecidas, quanto mais de coisas nunca feitas antes"104. São imprevisíveis as inovações geradas. Como "as áreas urbanas com diversidade emergente geram usos desconhecidos e imprevisíveis e perspectivas visuais peculiares" $^{105}$. Como são imprevisíveis o sucesso e os efeitos das inovações ${ }^{106}$, e os efeitos negativos, os próximos desafios, como fora a chuva ácida com os automóveis e o esgotamento do solo dos povos agrícolas ${ }^{107}$.

Por isso ela defende que as cidades são agentes dinâmicos na resolução de seus próprios problemas, criando novas tecnologias para desafios inéditos ${ }^{108}$. Os sucessos são claros apenas a posteriori: o primeiro barco a vapor e os primeiros automóveis foram desdenhados, a IBM não acreditava no computador pessoal, os especialistas em materiais industriais rejeitaram o plástico; mesmo a eletricidade adotou-se de maneira titubeante ${ }^{109}$. Quanto mais agentes experimentarem randomicamente possibilidades, melhor. A concentração das decisões em poucos centros, empresas ou governo, asfixia essa investigação, como o programa nuclear nos Estados Unidos, ou o do fim das navega-
102 JACOBS, 2004, p.23 - tradução nossa.

103 Depois incidirá sobre outras formas do que julgava ser "pseudo-ciência" (JACOBS, 2004).

104 JACOBS, 2001, p.170.

105 JACOBS, 2003, p.262.

106 Aqui temos outro enlace intencional com os avanços científicos. Cita nominalmente Edward Lorenz e a expressão que ficou conhecida do "efeito borboleta" (JACOBS, 2001).

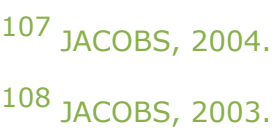

109 JACOBS, 2001 
110 JACOBS, 2004.

111 JACOBS, 1970.

112 JACOBS, 1970. ções interoceânicas na altamente centralizada China, contrastando com as viagens de Cristóvão Colombo, viáveis apenas porque houve uma variedade de possíveis patronos a quem oferecer o projeto ${ }^{110}$. Daí a tentativa e erro ser processo ao mesmo tempo necessário e incerto.

O desenvolvimento de atividades é um processo confuso e que consume tempo e energia em tentativa, erro e falha. As únicas certezas nele são a tentativa e o erro. O sucesso não é uma certeza. (JACOBS, 1970, p.90 - tradução nossa).

Porém esse processo tentativo acarreta um custo a ser arcado pelo organismo:

O que faz o processo caro é o grande número de empresas que devem encontrar capital inicial - incluindo aquelas que não serão bem sucedidas - e o grande número que precisa encontrar somas relativamente largas de capital de crescimento assim que iniciarem a prosperar. (JACOBS, 1970, p.228 - tradução nossa).

Por isso que a longo prazo os sistemas mais complexos são os que sobrevivem mais. Aqueles com a capacidade de se desenvolver, ganhar complexidade, ao curso do tempo, absorvendo o ruído do meio como estímulo, saltando de patamar em patamar. Assim, Manchester, cidade inteiramente dedicada à indústria têxtil em certo momento, faliu, enquanto Birmingham, vista então como caótica e ineficiente, sobreviveu, alterando seu perfil econômico a partir da infinidade de empresas que possuía, assim como a igualmente "caótica" Londres ${ }^{111}$. Dinâmica análoga à da ainda pujante Boston e a decadente Detroit, praticamente uma company town. O mesmo fenômeno ocorre com as grandes companhias, menos inovadoras que as pequenas, mesmo com $P \& D^{112}$. A especialização está longe do ideal; é a própria estagnação em ação.

\section{Conclusão}

A primeira obra de Jacobs já traz no título o cerne de suas aspirações e temores: a vida e a morte. Suas investigações subseqüentes Ihe apontarão uma importância ainda maior das cidades, como os dínamos que movimentam a economia planetária. Para ela, as cidades dinâmicas apóiam-se em outras cidades, mais antigas. Não se desenvolvem simultaneamente, estando em etapas diferentes. Enquanto as cidades antigas decaem, novas estão ascendendo. De um lado, a ameaça de uma espécie de morte térmica planetária, de uma Idade das Trevas logo adiante. 


\begin{abstract}
Se a estagnação global das cidades algum dia ocorrer, inexoravelmente fará com que a vida econômica estagne e se deteriore em todas as partes, e não haverá saída: nenhuma cidade pujante para intervir, nem jovens cidades surgindo enquanto ainda têm oportunidade para fazê-lo. Se isso ocorrer, podemos estar seguros que com a prática de desenvolver economias urbanas, a memória de como a coisa é feita também se desvanecerá, e logo depois, a crença de que pode ser feita por pessoas perfeitamente ordinárias não mais será tida como possível. De fato, não é tida como possível em boa parte do mundo mesmo hoje. (...) Todos temos nossos pesadelos sobre o futuro da vida econômica; este é o meu. (JACOBS, 1984, p. 134 - tradução nossa).
\end{abstract}

A mesma concepção aponta para uma perspectiva muito maior, agora no sentido do tempo. Todo ente complexo descende de algum outro, e assim sucessivamente. New York e Hong Kong, quando jovens, tinham como mercado Londres. Veneza, que em seu auge era mercado para as demais cidades européias, ganhou seu ímpeto ao ter como mercado Constantinopla e consolidadas cidades islâmicas ${ }^{113}$. As cidades fazem parte de uma cadeia evolutiva de recursos, de energia, por meio da troca econômica, uma longa cadeia histórica das cidades, onde às vezes a diversidade da rede se perde e se reduz a umas poucas, e às vezes floresce uma constelação de cidades.

Se Carl Sagan afirmava que somos todos pó de estrelas, e se todo e cada ser vivo do planeta descende de um mesmo ancestral, do primeiro organismo vivo que teria emergido na noite dos tempos, toda cidade descende daqueles primeiros assentamentos neolíticos, como Çatal Hüyük.

O que estou dizendo é que toda cidade tem um ancestral econômico direto, um parentesco econômico literal, em uma cidade ou cidades ainda mais velhas. Novas cidades não surgem por geração espontânea. A centelha da vida econômica urbana é passada de cidades mais velhas para as mais novas. Vive ainda hoje em cidades cujos ancestrais há muito se tornaram pó. (JACOBS, 1970, p.178 - tradução nossa).

E esta é uma perspectiva no mínimo luminosa.

\title{
Referências
}

GLEICK, James. Caos - A Criação de uma Nova Ciência. 4. ed. Rio de Janeiro: Campus, 1991.

ELLERMAN, David. Jane Jacobs on Development. Mar 2004. Disponível em: <http.//www. ellerman.org>. Último acesso em: 15 nov 2017. 
HOSPERS, Gert-Jan. Jane Jacobs - her life and work. European Planning Studies.v.14, n.6, jul 2006. Disponível em: <http.//www.preservenet.com/theory/Jacobsbiox.html> Último acesso em: 15 nov. 2017.

JACOBS, Jane. A Natureza das Economias. São Paulo: Beca Produções Culturais, 2001.

JACOBS, Jane. Cities and the Wealth of Nations: Principles of Economic Life. New York: Random House, 1984.

JACOBS, Jane. Dark Age Ahead. New York: Random House, 2004.

JACOBS, Jane. Morte e Vida de Grandes Cidades. São Paulo: Ed. Martins Fontes, 2003.

JACOBS, Jane. Systems of Survival: A Dialogue on the Moral Foundations of Commerce and Politics. New York: Random House, 1994.

JACOBS, Jane. The Economy of Cities. New York: First Vintage Books Edition, 1970.

JACOBS, Jane. The Question of Separatism. New York: Random House, 1980.

JOHNSON, Steven. Emergência - a vida integrada de formigas, cérebros, cidades e softwares. Rio de Janeiro: Jorge Zahar Editor, 2003.

LANG, Glenna \& WUNSCH, Marjory. Genius of common sense: Jane Jacobs and the story of The death and life of great American cities. Boston: David R. Godine, Publisher, 2009.

PAZ, Daniel J. Mellado. A Grande Cidade Americana de Jane Jacobs: um modelo de auto-organização emergente. In: Anais do II Seminário Internacional Urbicentros. Maceió: Editora da Universidade Federal de Alagoas, 2011 a.

PAZ, Daniel J. Mellado. Jane Jacobs e o Desafio das Cidades: uma teoria geral para o desenvolvimento urbano. In: Anais do II Seminário Internacional Urbicentros. Maceió: Editora da Universidade Federal de Alagoas, 2011b.

PRIGOGINE, Ilya Prigogine. As Leis do Caos. São Paulo: Ed. UNESP, 2002.

ROWE, Mary. Jane Jacobs and the Self-Organizing City. In: SCHUBERT, Dirk (ed.). Contemporary Perspectives on Jane Jacobs: reassessing the impacts of an urban visionary. Burlington, USA/ Surrey, England: Ashgate Publishing Company/ Ashgate Publishing Limited, 2014.

SCHUBERT, Dirk. 50 Years: "The Death and Life of Great American Cities". In: SCHUBERT, Dirk (ed.). Contemporary Perspectives on Jane Jacobs: reassessing the impacts of an urban visionary. Burlington, USA/ Surrey, England: Ashgate Publishing Company/ Ashgate Publishing Limited, 2014.

WEAVER, Warren. A Quarter Century In The Natural Sciences. Public Health Report, Vol. 76, N.1, January, 1961. Excerpted from his report which is included in The President's Review, a part of the Rockefeller Foundation's annual report of 1958.

WIENER, Norbert. Cibernética. São Paulo: Polígono e Universidade de São Paulo, 1970.

WIENER, Norbert. Cibernética e Sociedade - o uso humano de sêres humanos. São Paulo: Ed. Cultrix, 2. ed., 1980. 